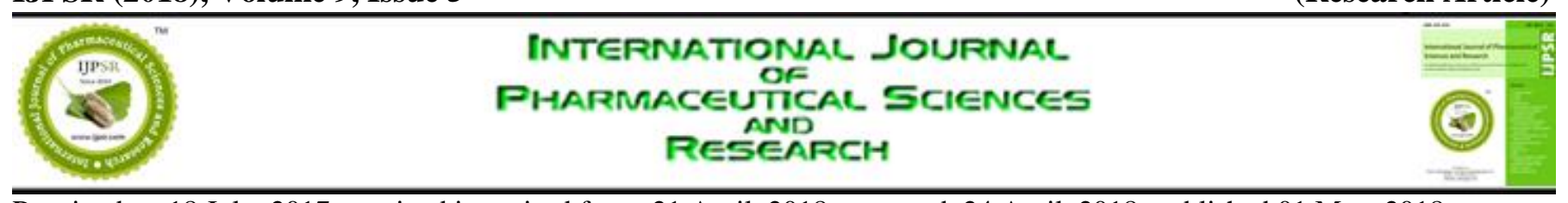

Received on 18 July, 2017; received in revised form, 21 April, 2018; accepted, 24 April, 2018; published 01 May, 2018

\title{
FORMULATION AND EVALUATION OF FLURBIPROFEN OCULAR IN-SITU GEL
}

\author{
Sravan Kumar Aligeti * , Raj Kumar Jampala and J. Vinaya
}

Vaageswari College of Pharmacy, (Affiliated to JNTUH, Hyderabad), Karimnagar - 505481, Telangana, India.

Keywords:

In-situ gelling systems, Flurbiprofen, Carbopol 934, Carbopol 940, Carbopol 971 and HPMC E15, HPMC K4M, and HPMC K100, pH sensitive systems, Ocular delivery

\section{Correspondence to Author:} Sravan Kumar Aligeti

Associate Professor,

Vaageswari College of

Pharmacy, Beside LMD Police

Station, Ramakrishna Colony,

Karimnagar - 505401,

Telangana, India.

E-mail: sravan.aligeti@gmail.com

\begin{abstract}
Conventional ophthalmic preparations exhibit poor bioavailability due to the rapid precorneal elimination of the drug, and the physiological constraints imposed by the protective mechanisms of the eye lead to the low absorption of the drugs resulting in a short duration of the therapeutic effect. In order to increase the residence time of the drug in-situ gelling systems were prepared and instilled as drops into the eye which undergo a sol-gel transition in the cul-de-sac. The present work describes the formulation and evaluation of flurbiprofen ocular in-situ gel, based on the concept of $\mathrm{pH}$ - triggered in-situ gelation. polyacrylic acid (carbopol) was used as the gelling agent in combination with hydroxy-propyl methyl cellulose (HPMC) which acted as a viscosity enhancing agent. The formulations were evaluated for clarity, $\mathrm{pH}$ measurement, gelling capacity, gelling temperature, drug content estimation, rheological study, in-vitro drug release study, sterility testing and stability studies. The physicochemical interactions between drug and polymers were investigated by fourier transform infrared (FTIR) spectroscopy. FTIR studies did not show any evidence of interaction between the drug and the polymers. The Formulation F22 (containing 1\% HPMC E15, 0.3\% carbopol 971) showed sustained release over a period of $8 \mathrm{~h}$ follows, first order mechanism.
\end{abstract}

INTRODUCTION: Topical application of drugs to the eye is the well established route of administration for the treatment of various eye diseases like dryness, conjunctiva, inflammation, eye flu etc. The protective mechanisms of the eye such as blinking, baseline and reflex lachrymation, and drainage decrease the bioavailability of drug and also help to remove rapidly foreign substances like the dust particles, including drugs, from the surface of the eye ${ }^{1}$.

\begin{tabular}{|l|c|}
\hline QUICK RESPONSE CODE & DOI: \\
\hline DOI link: http://dx.doi.org/10.13040/IJPSR.0975-8232.9(5).1851-56 \\
\hline
\end{tabular}

Topically applied drugs do not reach the posterior segment of the eye (retina, vitreous, choroid); therefore systemic administration, per ocular or intraocular injections of drugs are normally applied in clinical therapeutics ${ }^{2}$. The unique anatomy and physiology of the eye and its protective barriers prevent the administered drugs from protecting into the target tissues.

There are many eye diseases which can affect the eye and also eye vision. Therefore marketed ophthalmic formulations are classified as conventional and non-conventional (novel) drug delivery systems ${ }^{3}$. There are most commonly available ophthalmic preparations such as drops and ointments which render $70 \%$ of the eye dosage formulations in the market. 
But these preparations when installed into the eye are rapidly drained away from the ocular surface due to blinking tear flow and lachrymal nasal drainage of the eye. Only a small amount of the drug is available for its therapeutic effect resulting in need for frequent application to the eye ${ }^{4}$. So to overcome these problems novel pharmaceutical ophthalmic formulations such as in-situ gel, nanoparticle ${ }^{5,6}$ liposome, nano suspension ${ }^{7,8}$, micro emulsion ${ }^{9}$, intophoresis and ocular inserts have been developed in last three decades to increase the bioavailability of the drug in a sustained and controlled manner.

Conventional ocular drug delivery systems like eye drops require frequent instillations to maintain a therapeutic drug level at the site of action, whereas, gels have difficulty in instillation into the eye. An alternative approach has been the application of in-situ gelling systems which are instilled in a liquid form and shift to a gel form in the cul-de-sac 11, 12. The phase transition is triggered by the $\mathrm{pH}$ of the tears, the temperature at the eye surface or the electrolytes present in the tear film. Ophthalmic use of non-steroidal antiinflammatory drugs (NSAIDs) offers several benefits after intraocular and refractive surgery ${ }^{13}$. NSAIDs also can reduce patients' intra - and postoperative pain; help maintain pupillary dilation, control inflammation after surgery. Flurbiprofen is a non-steriodal anti- inflammatory drug used to treat eye infections such as corneal ulcers, seasonal allergic conjunctivitis and reduce inflammation following cataract surgery.

MATERIALS AND METHODS: Flurbiprofen, carbopol (934, 940 and 971), HPMC (E15, K4M, K100) and ethanol.

\section{Preparation of in-situ Gels of Flurbiprofen:} Aqueous solutions of varying concentrations of different polymers and drug were prepared and evaluated for gelling capacity and viscosity in order to identify the compositions suitable for use as in situ gelling systems.

All ingredients were weighed accurately and the formulations were prepared by dispersing different grades of polymers carbopol (934, 940 and 971) solutions in different concentrations $(0.1 \% \mathrm{w} / \mathrm{v}$, $0.3 \% \mathrm{w} / \mathrm{v}$, and $0.5 \% \mathrm{w} / \mathrm{v})$ and HPMC (E15, K4M and $\mathrm{K} 100)$ solutions in different concentrations $(1 \% \mathrm{w} / \mathrm{v}$ and $1.5 \% \mathrm{w} / \mathrm{v})$ in distilled water with continuous stirring until completely dispersed and allowed to hydrate overnight. Flurbiprofen $(0.03 \%)$ was dissolved in $0.5 \mathrm{ml}$ of ethanol and then added to the above polymeric solutions under constant stirring to obtain a uniform solution.

TABLE 1: COMPOSITION OF IN-SITU GELLING SYSTEMS BY pH SENSITIVE SYSTEMS

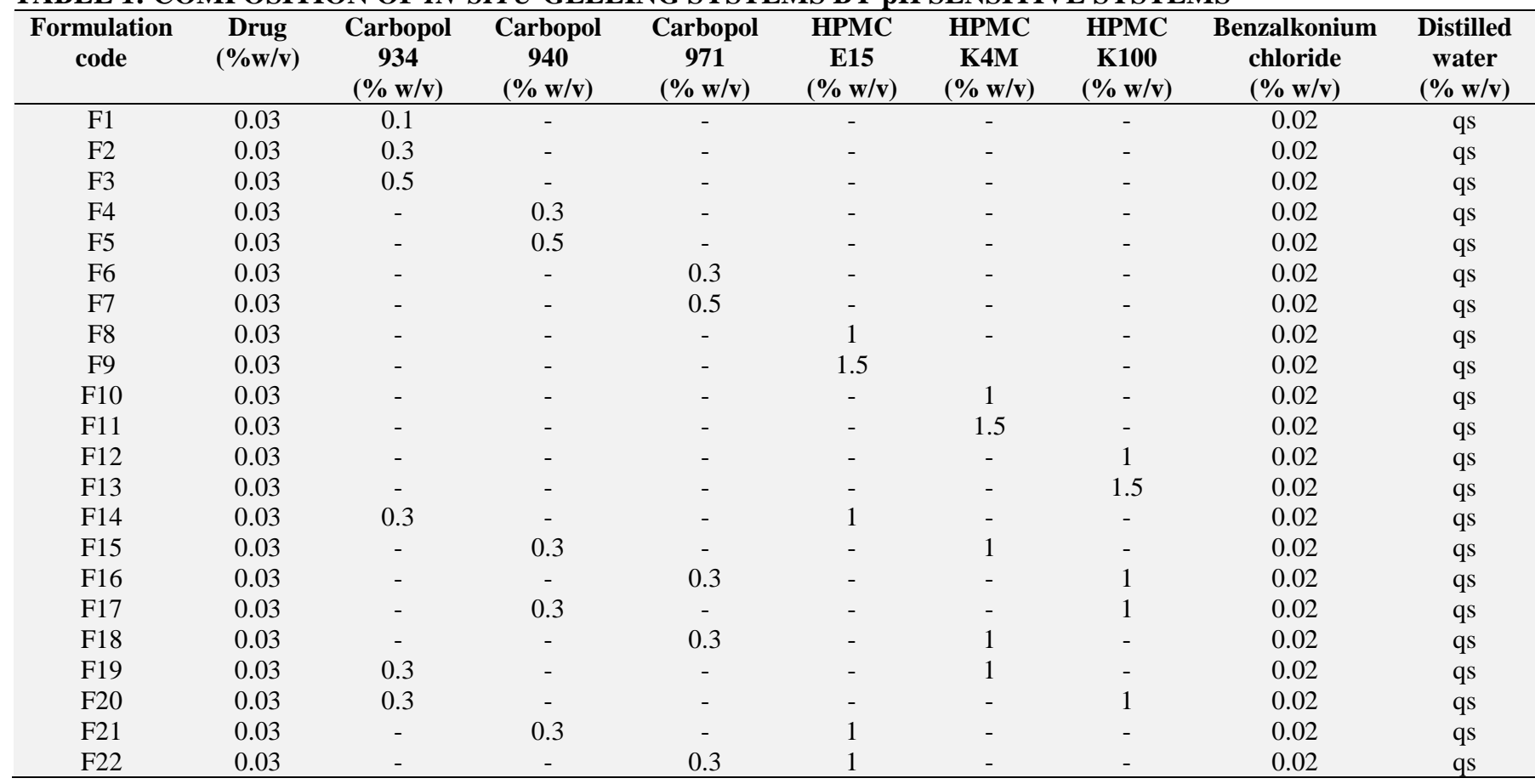

*qs to $100 \mathrm{ml}$ 
The $\mathrm{pH}$ of the solution was adjusted to 7.4 using $0.1 \mathrm{~N} \mathrm{NaOH}$ solution. Benzalkonium chloride (BKC) was then added to the above solution and mixing was confirmed until uniform and clear obtained. Final volume was made up by adding required amount of distilled water. All the formulations were terminally sterilized by autoclaving at $121^{\circ} \mathrm{C}$ and $15 \mathrm{lb}$ for $15 \mathrm{~min}$.

\section{Evaluation of Ocular in-situ Gels:}

Clarity: The clarity of the formulations before and after gelling was determined by visual examination of the formulations under light alternatively against white and black backgrounds.

pH: The developed ophthalmic formulations were evaluated for $\mathrm{pH}$ using digital $\mathrm{pH}$ meter. Ophthalmic formulations should have a $\mathrm{pH}$ range in between 4.0 - 7.4 .

Drug Content: Ocular in-situ gel of flurbiprofen was assayed by spectrophotometric analysis. The formulation $(1 \mathrm{ml})$ was taken in a $100 \mathrm{ml}$ volumetric flask diluted with simulated tear fluid (STF) pH 7.4 and was shaken to dissolve the drug in STF $\mathrm{pH}$ 7.4. The solution was filtered through Whatman filter paper; this filtrate was further diluted if necessary with PBS pH 7.4. Drug content was determined using a shimadzu UV 1800 double beam spectrophotometer at $247 \mathrm{~nm} .^{5}$

Measurement of Gelling Capacity: The prepared in-situ gelling system was evaluated for gelling capacity in order to identify the composition suitable for use as in-situ gelling systems. The insitu gelling system was mixed with simulated tear fluid (in the proportion of 25:7 which means the application volume of $25 \mu \mathrm{l}$ and normal volume of tear fluid in the eye is $7 \mu$ l) to find out the gelling capacity of the ophthalmic product. The gelation was then visually assessed by noting the time for gelation and time taken for the gel formed to dissolve.

TABLE 2: EVALUATION OF CLARITY, pH, DRUG CONTENT AND GELLING CAPACITY OF ALL FORMULATIONS

\begin{tabular}{ccccc}
\hline $\begin{array}{c}\text { Formulation } \\
\text { code }\end{array}$ & Clarity & pH & $\begin{array}{c}\text { Drug } \\
\text { content }\end{array}$ & $\begin{array}{c}\text { Gelling } \\
\text { capacity }\end{array}$ \\
\hline F1 & Clear & 7.2 & $98.3 \pm 1.1$ & + \\
F2 & Clear & 7.0 & $99.7 \pm 1.2$ & + \\
F3 & Clear & 7.3 & $101.3 \pm 0.9$ & ++ \\
F4 & Clear & 7.0 & $97.9 \pm 1.3$ & ++ \\
F5 & Clear & 7.0 & $99.9 \pm 1.1$ & ++ \\
F6 & Clear & 7.1 & $99.3 \pm 0.9$ & ++ \\
F7 & Clear & 7.2 & $99.5 \pm 0.5$ & +++ \\
F8 & Clear & 7.0 & $98.5 \pm 0.6$ & ++ \\
F9 & Clear & 7.1 & $99.1 \pm 0.1$ & ++ \\
F10 & Clear & 6.9 & $98.7 \pm 1.1$ & + \\
F11 & Clear & 6.7 & $99.1 \pm 0.3$ & + \\
\hline
\end{tabular}

TABLE 3: EVALUATION OF CLARITY, pH, DRUG CONTENT AND GELLING CAPACITY OF ALL FORMULATIONS

\begin{tabular}{ccccc}
\hline $\begin{array}{c}\text { Formulation } \\
\text { code }\end{array}$ & Clarity & pH & $\begin{array}{c}\text { Drug } \\
\text { content }\end{array}$ & $\begin{array}{c}\text { Gelling } \\
\text { capacity }\end{array}$ \\
\hline F12 & Cloudy & 6.5 & $102.3 \pm 0.2$ & $\mathrm{~S}$ \\
F13 & Cloudy & 6.6 & $98.7 \pm 0.6$ & $\mathrm{~S}$ \\
F14 & Clear & 7.3 & $98.7 \pm 1.1$ & ++ \\
F15 & Clear & 7.1 & $98.5 \pm 0.7$ & ++ \\
F16 & Cloudy & 6.8 & $96.5 \pm 0.5$ & $\mathrm{~S}$ \\
F17 & Cloudy & 6.7 & $97.5 \pm 1.1$ & $\mathrm{~S}$ \\
F18 & Clear & 7.0 & $99.1 \pm 1.3$ & + \\
F19 & Clear & 7.1 & $98.4 \pm 1.3$ & + \\
F20 & Cloudy & 6.9 & $99.5 \pm 1.0$ & $\mathrm{~S}$ \\
F21 & Clear & 7.2 & $99.6 \pm 1.0$ & + \\
F22 & Clear & 7.4 & $99.5 \pm 0.5$ & +++ \\
\hline
\end{tabular}

*Mean \pm SD, $\mathrm{n}=3$, “+”": gels after a few minutes, dissolves rapidly; "++": gelation immediate, remains for few hours; " +++ ": gelation immediate, remains for extended period; "s": gelation immediate, remains for extended period but gels are stiff

TABLE 4: EVALUATION OF VISCOSITY OF ALL FORMULATIONS

\begin{tabular}{|c|c|c|c|c|c|}
\hline \multirow{2}{*}{$\begin{array}{l}\text { Formulation } \\
\text { code }\end{array}$} & \multicolumn{2}{|c|}{ Viscosity (cp) at $20 \mathrm{rpm}$} & \multirow{2}{*}{$\begin{array}{c}\text { Formulation } \\
\text { code }\end{array}$} & \multicolumn{2}{|c|}{ Viscosity (cp) at $20 \mathrm{rpm}$} \\
\hline & $\begin{array}{c}\text { Before gelation } \\
\left(25^{\circ} \mathrm{C}\right)\end{array}$ & $\begin{array}{c}\text { After gelation } \\
\left(37^{\circ} \mathrm{C}\right)\end{array}$ & & $\begin{array}{c}\text { Before gelation } \\
\left(25^{\circ} \mathrm{C}\right)\end{array}$ & $\begin{array}{c}\text { After gelation } \\
\left(37^{\circ} \mathbf{C}\right)\end{array}$ \\
\hline F1 & 117 & 980 & F12 & 912 & 2166 \\
\hline $\mathrm{F} 2$ & 192 & 1128 & F13 & 989 & 2331 \\
\hline F3 & 675 & 2005 & F14 & 698 & 1433 \\
\hline $\mathrm{F} 4$ & 586 & 2341 & F15 & 735 & 1554 \\
\hline F5 & 600 & 1468 & F16 & 1003 & 2443 \\
\hline F6 & 656 & 1669 & F17 & 1243 & 2256 \\
\hline F7 & 768 & 1985 & F18 & 512 & 1992 \\
\hline F8 & 832 & 1764 & F19 & 326 & 1008 \\
\hline F9 & 884 & 2052 & $\mathrm{~F} 20$ & 1126 & 2892 \\
\hline F10 & 497 & 1296 & F21 & 776 & 2257 \\
\hline F11 & 634 & 1945 & & & \\
\hline
\end{tabular}


Rheological Studies: Rheological studies were conducted using a Brookfield synchroelectric viscometer (LVDV Pro II). The developed formulation was poured into the small sample adaptor of the brookfield synchroelectric viscometer ${ }^{11}$ and the viscosity was measured at non-physiological ( $\mathrm{pH} 4$ and $25{ }^{\circ} \mathrm{C}$ ) and physiological condition ( $\mathrm{pH} 7.4$ and $37^{\circ} \mathrm{C}$ ) respectively.

TABLE 5: VISCOSITIES OF OPTIMIZED IN-SITU GEL FORMULATIONS AT DIFFERENT RPM

\begin{tabular}{ccc}
\hline \multicolumn{2}{c}{ F22 } \\
\hline \multirow{2}{*}{ RPM } & \multicolumn{2}{c}{ Viscosty $(\mathbf{c p})$} \\
\cline { 2 - 3 } & Before gelation $\left(\mathbf{2 5}{ }^{\circ} \mathbf{C}\right)$ & After gelation $\left(\mathbf{3 7}^{\circ} \mathbf{C}\right)$ \\
\hline 10 & 300 & 1026 \\
20 & 274 & 980 \\
30 & 215 & 880 \\
50 & 192 & 653 \\
100 & 145 & 540 \\
\hline
\end{tabular}

In-vitro Diffusion Studies: In-vitro drug release study of the formulation was carried out by diffusion process. It was performed on Franz diffusion cell using semi permeable membrane was soaked overnight in the receptor medium (STF, pH 7.4) and tied to one end of the glass diffusion cell.

TABLE 6: IN-VITRO DRUG RELEASE PROFILE OF FORMULATION F1 TO F4

\begin{tabular}{ccccc}
\hline Time-h & F1 & F2 & F3 & F4 \\
\hline 1 & $3.20 \pm 1.150$ & $9.61 \pm 2.423$ & $14.5 \pm 2.995$ & $18.9 \pm 1.885$ \\
2 & $4.81 \pm 2.000$ & $13.9 \pm 2.905$ & $18.2 \pm 3.756$ & $27.1 \pm 4.108$ \\
3 & $7.11 \pm 2.189$ & $18.4 \pm 3.196$ & $25.1 \pm 1.015$ & $32.5 \pm 3.392$ \\
4 & $10.8 \pm 2.469$ & $23.2 \pm 3.007$ & $30.6 \pm 2.027$ & $37.2 \pm 3.407$ \\
5 & $14.3 \pm 2.852$ & $28.2 \pm 4.467$ & $35.6 \pm 2.955$ & $42.6 \pm 4.107$ \\
6 & $18.9 \pm 3.569$ & $32.1 \pm 3.049$ & $41.6 \pm 3.307$ & $48.8 \pm 4.657$ \\
7 & $23.2 \pm 4.400$ & $34.4 \pm 3.881$ & $46.5 \pm 3.968$ & $54.2 \pm 3.510$ \\
8 & $28.2 \pm 4.914$ & $36.8 \pm 4.883$ & $51.9 \pm 4.086$ & $60.0 \pm 2.885$ \\
\hline
\end{tabular}

TABLE 7: IN-VITRO DRUG RELEASE PROFILE OF FORMULATION F5 TO F8

\begin{tabular}{ccccc}
\hline Time-h & F5 & F6 & F7 & F8 \\
\hline 1 & $31.0 \pm 2.516$ & $26.5 \pm 1.607$ & $36.8 \pm 0.642$ & $23.2 \pm 0.916$ \\
2 & $42.6 \pm 1.882$ & $29.4 \pm 1.587$ & $42.2 \pm 2.005$ & $30.5 \pm 1.527$ \\
3 & $50.6 \pm 3.000$ & $34.8 \pm 1.677$ & $44.9 \pm 3.066$ & $31.9 \pm 1.050$ \\
4 & $54.4 \pm 2.008$ & $44.5 \pm 1.607$ & $51.1 \pm 2.150$ & $36.8 \pm 1.527$ \\
5 & $57.3 \pm 1.401$ & $50.0 \pm 2.081$ & $57.3 \pm 1.686$ & $42.4 \pm 2.523$ \\
6 & $63.9 \pm 0.550$ & $52.3 \pm 3.027$ & $62.6 \pm 2.884$ & $46.5 \pm 4.700$ \\
7 & $67.3 \pm 1.527$ & $56.7 \pm 2.502$ & $67.4 \pm 3.094$ & $51.3 \pm 3.482$ \\
8 & $69.7 \pm 2.400$ & $62.4 \pm 3.055$ & $70.9 \pm 2.951$ & $60.1 \pm 2.950$ \\
\hline
\end{tabular}

TABLE 8: IN-VITRO DRUG RELEASE PROFILE OF FORMULATION F9 TO F12

\begin{tabular}{ccccc}
\hline Time-h & F9 & F10 & F11 & F12 \\
\hline 1 & $8.10 \pm 1.185$ & $12.5 \pm 1.054$ & $8.10 \pm 2.042$ & $11.2 \pm 1.442$ \\
2 & $11.2 \pm 1.845$ & $18.6 \pm 2.950$ & $11.4 \pm 2.081$ & $16.6 \pm 3.353$ \\
3 & $13.5 \pm 1.755$ & $25.1 \pm 1.648$ & $17.7 \pm 2.451$ & $25.1 \pm 2.478$ \\
4 & $18.4 \pm 1.379$ & $33.5 \pm 1.250$ & $23.8 \pm 1.594$ & $36 \pm 2.605$ \\
5 & $24.8 \pm 1.267$ & $40.6 \pm 2.100$ & $32.3 \pm 2.370$ & $46.8 \pm 3.686$ \\
6 & $29.8 \pm 3.511$ & $48.4 \pm 2.708$ & $36.6 \pm 3.931$ & $52.3 \pm 4.005$ \\
7 & $34.4 \pm 2.500$ & $56.2 \pm 4.574$ & $45.7 \pm 1.824$ & $57.7 \pm 2.930$ \\
8 & $44.5 \pm 4.273$ & $68.9 \pm 1.606$ & $50.7 \pm 2.605$ & $65.8 \pm 2.461$ \\
\hline
\end{tabular}

The donar compartment was filled with $1 \mathrm{ml}$ formulation and the receptor compartment was filled with $25 \mathrm{ml}$ of simulated tear fluid, assuring that the membrane was just touched the receptor surface. The whole assembly was adjusted on a magnetic stirrer and the temperature was maintained at $34 \pm 0.5{ }^{\circ} \mathrm{C}$. Aliquots were diluted with the stimulated tear fluid and analyzed by UVvisible spectrophotometer at $247 \mathrm{~nm}$.

TABLE 9: IN-VITRO DRUG RELEASE PROFILE OF FORMULATION F13 TO F16

\begin{tabular}{ccccc}
\hline Time-h & F13 & F14 & F15 & F16 \\
\hline 1 & $10.0 \pm 1.958$ & $5.80 \pm 1.539$ & $10.3 \pm 2.225$ & $7.70 \pm 1.692$ \\
2 & $16.6 \pm 2.802$ & $12.5 \pm 1.654$ & $16.2 \pm 5.040$ & $16.6 \pm 4.080$ \\
3 & $24.7 \pm 3.254$ & $17.8 \pm 4.088$ & $28.6 \pm 3.358$ & $29.6 \pm 3.840$ \\
4 & $28.2 \pm 3.561$ & $28.6 \pm 2.753$ & $36.9 \pm 3.111$ & $37.5 \pm 4.349$ \\
5 & $32.5 \pm 4.181$ & $36.9 \pm 3.922$ & $45.7 \pm 2.897$ & $47.0 \pm 2.884$ \\
6 & $37.7 \pm 3.892$ & $46.5 \pm 3.288$ & $54.2 \pm 3.401$ & $53.4 \pm 2.326$ \\
7 & $45.1 \pm 4.443$ & $53.8 \pm 4.440$ & $68.4 \pm 0.949$ & $61.6 \pm 3.709$ \\
8 & $53.4 \pm 3.357$ & $67.4 \pm 3.635$ & $72.8 \pm 1.038$ & $65.0 \pm 2.599$ \\
\hline
\end{tabular}

TABLE 10: IN-VITRO DRUG RELEASE PROFILE OF FORMULATION F17 TO F21

\begin{tabular}{cccccc}
\hline Time-h & F17 & F18 & F19 & F20 & F21 \\
\hline 1 & 8.43 & 12.5 & 10.4 & 7.30 & 11.2 \\
& \pm 2.851 & \pm 3.151 & \pm 3.511 & \pm 0.862 & \pm 1.442 \\
2 & 14.8 & 18.9 & 16.2 & 14.3 & 15.5 \\
& \pm 4.132 & \pm 4.279 & \pm 3.991 & \pm 1.950 & \pm 2.753 \\
3 & 21.3 & 26.7 & 28.6 & 22.4 & 24.8 \\
& \pm 2.321 & \pm 4.955 & \pm 3.597 & \pm 2.951 & \pm 4.233 \\
4 & 25 & 33.3 & 35.4 & 27.5 & 29.8 \\
& \pm 3.908 & \pm 4.755 & \pm 4.009 & \pm 2.876 & \pm 2.882 \\
5 & 32.5 & 43.6 & 41.6 & 34.1 & 36.6 \\
& \pm 3.774 & \pm 5.118 & \pm 4392 & \pm 4.324 & \pm 3.941 \\
6 & 35.6 & 51.1 & 47.6 & 42.6 & 44.3 \\
& \pm 5.641 & \pm 4.352 & \pm 5.296 & \pm 3.222 & \pm 3.959 \\
7 & 45.7 & 61.6 & 57.7 & 50.9 & 60.3 \\
& \pm 4.654 & \pm 3.154 & \pm 3.745 & \pm 2.615 & \pm 4.639 \\
8 & 51.5 & 67.8 & 64.3 & 60.4 & 63.9 \\
& \pm 4.669 & \pm 3.514 & \pm 4.720 & \pm 2.142 & \pm 4.824 \\
\hline
\end{tabular}

\section{Optimised Formula:}

TABLE 11: IN-VITRO DRUG RELEASE PROFILE OF FORMULATION F22

\begin{tabular}{cc}
\hline Time-h & \% Drug release \\
\hline 0 & $0 \pm 0.00$ \\
1 & $16.2 \pm 1.15$ \\
2 & $30.5 \pm 2.67$ \\
3 & $55.6 \pm 3.87$ \\
4 & $60.5 \pm 3.57$ \\
5 & $69.7 \pm 2.98$ \\
6 & $76.6 \pm 4.34$ \\
7 & $80.5 \pm 3.85$ \\
8 & $86.7 \pm 4.97$ \\
\hline
\end{tabular}

\section{Sterility Studies:}

TABLE 12: TEST OF STERILITY

\begin{tabular}{cccccccc}
\hline \multirow{2}{*}{$\begin{array}{c}\text { Formulation } \\
\text { code }\end{array}$} & $\mathbf{1}$ & $\mathbf{2}$ & $\mathbf{3}$ & $\mathbf{4}$ & $\mathbf{5}$ & $\mathbf{6}$ & $\mathbf{7}$ \\
\cline { 2 - 8 } & - & - & - & - & - & - & - \\
T5 & - & - & - & - & - & - & - \\
\hline
\end{tabular}

Where " - " sign indicate no growth 


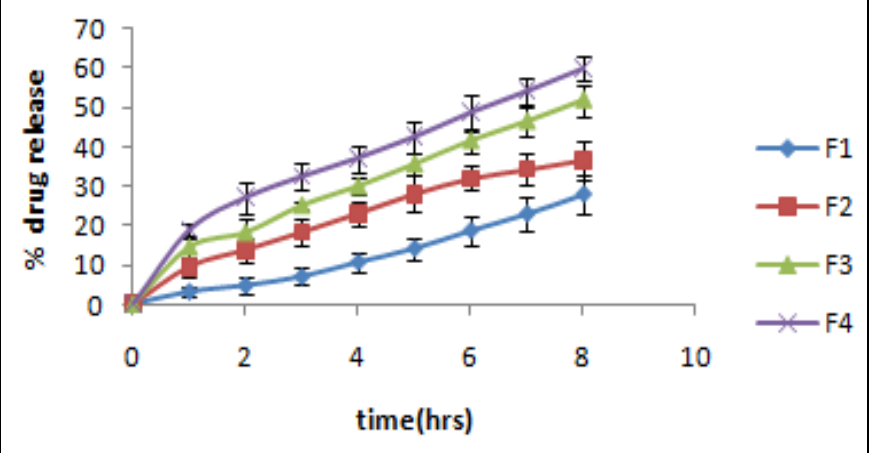

FIG. 1: IN-VITRO DRUG RELEASE PROFILE OF FORMULATION F1 TO F4

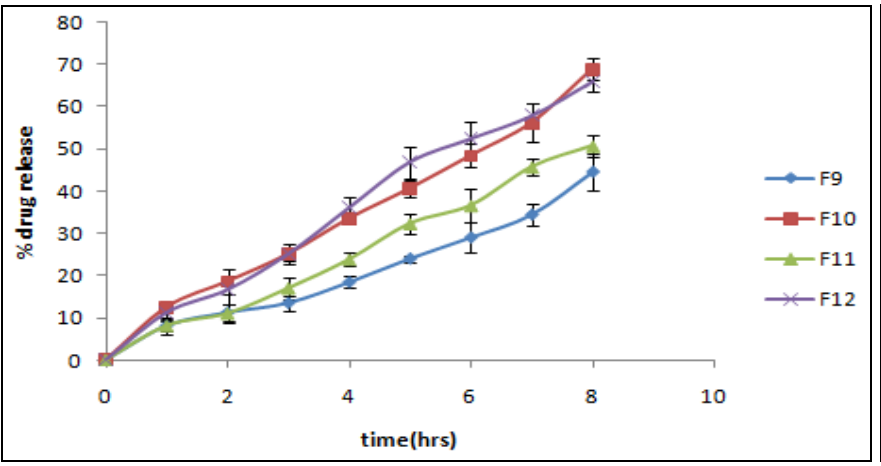

FIG. 3: IN-VITRO DRUG RELEASE PROFILE OF FORMULATION F9 TO F12

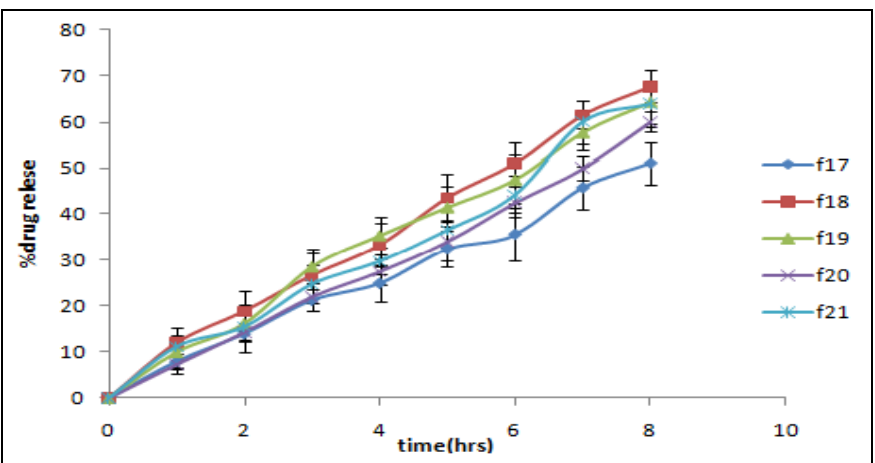

FIG. 5: IN-VITRO DRUG RELEASE PROFILE OF FORMULATION F17 TO F21

The optimised formulation F22 were evaluated for the sterility. After 7 days of incubation the results showed no microbial growth in the formulation.

CONCLUSION: In this study, ophthalmic in situ gelling system of flurbiprofen was successfully formulated with polymers carbopol 934, carbopol 940, carbopol 971 and HPMC E15, HPMC K4M, HPMC K100 for $\mathrm{pH}$ - triggered in-situ gelling system. Flurbiprofen, is a non-steriodal antiinflammatory agent used in the treatment of ocular inflammations. Optimized formulation F22, flurbiprofen $(0.03 \% \mathrm{w} / \mathrm{v} \%)$ using carbopol 971 $(0.3 \% \mathrm{w} / \mathrm{v} \%)$ as a gelling agent in combination with HPMC E15 (1\% w/v) as a viscosity enhancing agent.

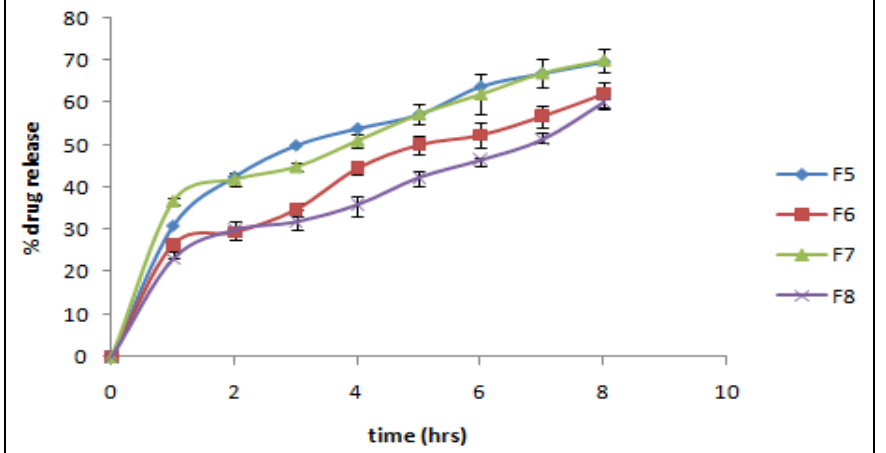

FIG. 2: IN-VITRO DRUG RELEASE PROFILE OF FORMULATION F5 TO F8

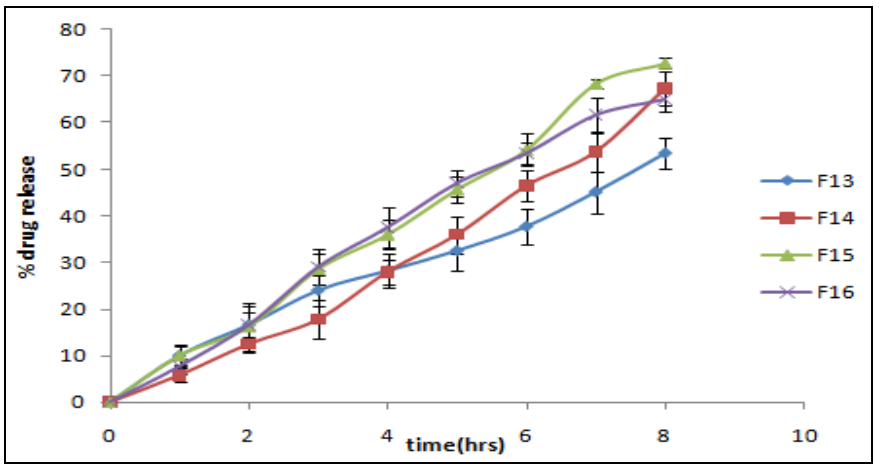

FIG. 4: IN-VITRO DRUG RELEASE PROFILE OF FORMULATION F13 TO F16

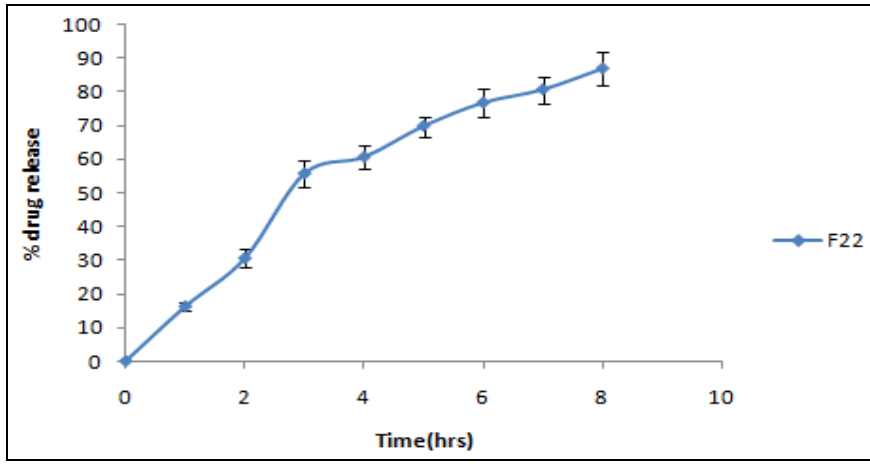

FIG. 6: IN-VITRO DRUG RELEASE PROFILE OF FORMULATION F22

The formulation underwent gelation in the cul-desac upon instillation as drops into the eyes. The formulation was found to be clear, having good in situ gelling capacity. Optimized formulation was sterile and showed sustained drug release over $8 \mathrm{~h}$ period. The formulation showed sustained drug release with prolonged drug residence time, thereby increasing the effectiveness of the drug by localization at the site of action.

ACKNOWLEDGEMENT: The first author is thankful to G. Srinivas Reddy chairman, Vaageswari Educational Society, Karimnagar, Telangana, India for providing infrastructure and research facilities. 


\section{CONFLICT OF INTEREST: The author reports} no conflicts of interest.

\section{REFERENCES:}

1. Kaur H, Loyee S and Garg R: Formulation and evaluation of in-situ ocular gel of gatifloxacin, Int J Pharma Res Health Sci. 2016; 4(5): 1365-1370.

2. Shaikh A, Farheen $\mathrm{T}$ and Shahi $\mathrm{S}$ : Formulation development and evaluation of $\mathrm{pH}$ triggered in situ ophthalmic gel of epinastine hydrochloride. IJPSR 2016; 7(3): 1131-1138.

3. Patil SK, Kadam A, Bandgar S and Patil SK: Formulation and evaluation of an in-situ gel for ocular drug delivery of anticonjunctival drug. Cellulose Chem. Technol. 2015; 49(1): 35-40.

4. Dol H, Gandhi S, Pardhi D and Vyawahare N: Formulation and evaluation of in-situ ophthalmic gel of moxifloxacin hydrochloride, The Pharma Innovation Journal 2014; 3(5): 60-6.

5. Makwana SB and Patel VA: Development and charectrizatio of in situ gel for opthlamic formulation containing ciprofloxacin hydrochloride. Results in Pharma Sciences 2015; 6: 1-6.
6. Shaikh et al.: Formulation development and evaluation of $\mathrm{pH}$ triggered in-situ ophthalmic gel of epinastine hydrochloride. IJPSR 2016; 7(3): 1131-1138.

7. Kaur $\mathrm{H}$ et al.: Formulation and evaluation of in-situ ocular gel of gatifloxacin. IJPRHS 2016; 4(5): 1365-1370.

8. Shahi and Deshpande: Iontophoresis: An approach to drug delivery enhancement, IJPSR 2017; 8(10): 4056-4068.

9. Dasankoppa FS et al.: Design, formulation, and evaluation of in-situ gelling ophthalmic drug delivery system comprising anionic nonionic polymers 2017;10(3):323-30.

10. Paradkar MU et al.: formulation development and evaluation of natamycin niosomal in-situ gel for ophthalmic drug delivery, Journal of Drug Delivery Science and Technology 2017; 39: 113e122.

11. Balasingam $\mathrm{R}$ et al.: Formulation of in-situ gelling system for ophthalmic delivery of erythromycin. International Journal of Students' Research in Technology and Management 2017; 5(3): 01-08.

12. Kotreka UK: Development of topical ophthalmic in-situ gelforming estradiol delivery system intended for the prevention of age-related cataracts PLOS ONE / journal. pone.0172306, 2017.

13. Saini R: In-situ gels - a new trends in ophthalmic drug delivery systems. International Journal of Pharma Sciences and Research (Ijpsr) 2015; 6(5): 886-890.

How to cite this article:

Aligeti SK, Jampala RK and Vinaya J: Formulation and evaluation of flurbiprofen ocular in-situ gel. Int J Pharm Sci \& Res 2018; 9(5): 1851-56. doi: 10.13040/ IJPSR.0975-8232.9(5).1851-56.

All @ 2013 are reserved by International Journal of Pharmaceutical Sciences and Research. This Journal licensed under a Creative Commons Attribution-NonCommercial-ShareAlike 3.0 Unported License.

This article can be downloaded to ANDROID OS based mobile. Scan QR Code using Code/Bar Scanner from your mobile. (Scanners are available on Google Playstore) 